\title{
RESPONSIBILITY AND EXCUSE IN MEDICINE AND LAW: A UTILITARIAN PERSPECTIVE
}

\author{
Seymour L. Halleck, M.D.*
}

\section{INTRODUCTION}

In its most common usage, the term "responsible" connotes blame or obligation. A statement that one is responsible for an act that has already happened, particularly if it is an act of which most people would disapprove, often means that the actor is blameworthy. A statement that one is responsible for future conduct often means that the actor incurs an obligation to behave in a certain way and that if the obligation is not met, blame will ultimately follow. The attribution of responsibility to an individual for a given act implies that the individual had the capacity to choose to perform or not perform that act. Only those who appear able to choose are found blameworthy or are held to their obligations. ${ }^{1}$

Social systems are strengthened by holding people responsible for their conduct. The legal system, for example, obligates citizens to behave in ways that minimize the risk of social harm. Citizens know that they will be held responsible, that is, blamed, and perhaps subjected to punitive sanctions if they do not behave in such ways. This knowledge presumably leads to lawabiding behavior. Every civilized society has also developed mechanisms for excusing from legal blame or obligation those who appear unable to exercise choice. In the criminal law excuses are based upon psychological or physical incapacities that diminish the actor's knowledge of the nature and consequences of socially proscribed acts or upon some unusual environmental influence (such as duress) that was present at the time such acts occurred. ${ }^{2}$

People may also be held responsible or excused for conduct that is not legally proscribed. In most social relationships, sanctions are imposed to designate blame or to hold people to obligations, but such relationships also allow for excusing from responsibility those who appear incapable of choice. ${ }^{3}$

Copyright (c) 1986 by Law and Contemporary Problems

- Professor of Medicine, University of North Carolina.

1. See J. Hall, General Principles of Criminal Law 460 (1960).

2. See generally D. Hermann, The Insanity Defense (1983).

3. C. Snyder, R. Higgins \& R. Stucky, Excuses: Masquerades in Search of Grace 4 (1983). The authors provide this useful definition of excuses in interpersonal processes: "Excuses are explanations or actions that lessen the negative implications of an actor's performance, thereby maintaining a positive image for oneself and others." 
The purpose of this article is to demonstrate how the process of blaming and excusing in criminal law can be better understood by examining an excusegiving system outside of the field of law, namely the system for treating medical patients. This system is important in its own right and I will describe why the process of assessing the responsibility of patients is an integral part of medical treatment. My primary reason for focusing upon excuse-giving in medicine, however, is that this process is similar to the process of excusegiving in law, and yet sufficiently different so as to provide new insights into alternative approaches to criminal justice.

II

\section{The Purpose of Blame or Excuse in Law and Medicine}

In the criminal law the process of invoking responsibility is ordinarily associated with a societal response involving punishment. This response fulfills the retributive function of the criminal law. There are four social purposes associated with the idea of retribution. First, societal punishment prevents private vengeance. Presumably, if society did not punish the perpetrators of criminal acts, victims might respond by creating new harms. Second, punishment teaches society the values of law and the importance of obeying the law. The public rejection, condemnation, or censure of the offender by society is a powerful lesson to all citizens. Third, punishment of the guilty clearly delineates responsibility for whatever wrong has occurred. Only the offender is guilty; all others are absolved of blame for the offender's act. Fourth, punishment seems to serve a powerful moral or emotional need for many members of the community. ${ }^{4}$ It is often argued that punishment must be imposed on those who have harmed society simply because they deserve it. This concept of "just desert" is often presumed to reside in a natural and immutable human need for justice. ${ }^{5}$

In the process of blaming and punishing, the criminal justice system also serves nonretributive and clearly utilitarian needs of the society and the offender. Punishment may deter the offender from subsequent criminal acts. The example of his punishment may also deter others. Punishment may also play a significant role in helping the offender see the error of his ways, and thus contribute to his ultimate reformation. Finally, some forms of punishment, such as imprisonment, also provide society with protection from the possibility that the criminal will offend again.

It is possible to accomplish the more utilitarian functions of the criminal justice system (specific and general deterrence, rehabilitation, and restraint) without holding the offender blameworthy and responsible. With the exception of those acquitted by reason of insanity, however, this separation of responsibility from punishment does not occur. In dealing with the majority of offenders, the criminal justice system mixes retributive and utilitarian

4. S. Kadish \& M. Paulsen, Criminal Law and Its Processes 5 (1983).

5. E. van den Haag \& J. Conrad, The Death Penalty: A Debate 55 (1983). 
purposes. ${ }^{6}$ The ascription of responsibility and blame leads to some type of retribution. Such retribution, however, is also calibrated to serve classical utilitarian goals so that the degree, the nature, and the locus of punishment are also determined by concern for deterrence, rehabilitation, or restraint.

Excuses from criminal responsibility are intended to promote the fairness of the judicial process by sparing from punishment those who lack the capacity to refrain from illegal conduct. In criminal law, excuses are rare. Once it is proven that an offender has committed a criminal act, he is at risk of punishment unless there is additional evidence that he honestly and reasonably believed he was performing a legal act (mistake of fact), he was forced into committing the act (duress), or he was insane at the time of the crime. $^{7}$

Medicine structures the process of ascribing responsibility to protect those who are disabled or to assist patients' recovery by excusing them from the stresses of blame or obligation. Physicians must evaluate a great deal of deviant and substandard conduct (failure to meet obligations) and determine if it is excusable. Because such behavior is not proscribed by law, the consequences of a decision not to excuse the conduct do not include criminal punishment. If it is not excusable, the patient may still be subject to the aversive consequences of blame (by self, family, friends, employers, or the community) or be required to meet future obligations. Excuses are most likely to be provided when physicians see disabilities related to substandard or deviant conduct as a form of illness. ${ }^{8}$ Because illness is so ubiquitous and is believed to influence so many varieties of behavior, medical excuses are very common. Physicians do not usually allow ascription of responsibility for substandard or deviant conduct until they have made exhaustive efforts to rule out the existence of an excusable illness.

When doctors make decisions to withhold or grant excuses, there is little or no mixing of retributive and utilitarian purposes. Physicians are rarely concerned with the question whether patients deserve excuses. Even when physicians withhold excuses, they do not intend to punish. The patient may perceive the consequences of not being excused as aversive, but the physician's intent is always to be helpful to the patient.

The physician's practices with regard to excuse-giving may also serve social purposes. Most societies have a strong interest in having as many citizens as possible meet their obligations. By failing to excuse individuals who claim to be sick, the physician encourages them to perform better. Excusing sick people from obligations such as work or military service has different social consequences. It may provide expanded opportunities or greater obligations for those who are not disabled. ${ }^{9}$

6. N. Morris, Madness and the Criminal Law 197 (1982).

7. H.L.A. HaRt, Punishment and Responsibility 29 (1968).

8. T. Szasz, Law, Liberty, and Psychiatry 13-15 (1963).

9. D. Stone, The Disabled State 5 (1984). 


\section{III}

\section{The Power of the Medical Excuse}

Most people, including doctors, do not look upon medical practice as a system that provides excuses from blame or obligation. The importance of excuse-giving can be illustrated, however, by considering the following, not uncommon, situation.

Several years ago I developed symptoms of low grade fever and extreme fatigue. I went to work each day for about two weeks but accomplished little. I worried about my condition and was especially concerned about preparing and delivering a major speech I was supposed to give in just a few days. When I finally realized that I was getting very little done, I reluctantly went to see my doctor. After performing a brief examination and doing blood tests, he informed me that I had a severe case of infectious mononucleosis with hepatitis. He told me that it was imperative that I quit trying to work and that I stay in bed for at least two weeks. My response to his diagnosis and recommendation was one of relief. I no longer blamed myself for my poor performance during the previous two weeks. I knew that if others were critical of my performance, my illness would blunt any negative feelings they might have been developing towards me. I was also excused from the obligation of continuing work. It then became possible for me not to meet my obligation to give my speech and still retain integrity. When I called the sponsors of the speech and my employers and told them about my illness, they were sympathetic and understanding. They told me to go to bed and wished me a speedy recovery. The medical excuse in this case was powerful and complete.

What would have happened if the doctor had detected no disease? I then would have had no honorable means of avoiding my obligations even if I felt incapable of meeting them. I would, in fact, have been exposed to substantial aversive consequences from several sources. Those who were depending on me for work or for my presentation would have been seriously troubled by my response. My credibility would have been damaged and if I behaved in a similar manner often enough my livelihood eventually might have been threatened. My family certainly would have had difficulty understanding why I was failing to meet my obligations. They would have blamed me for having spent the previous two weeks doing nothing. It is likely that my physician would also have treated me less indulgently. Absent the finding of physical disease, he probably would have viewed my difficulty in meeting obligations as either a manifestation of a mild emotional disorder or as laziness. In either case, my behavior would have been judged as being much more subject to my own control, less "respectable," and perhaps blameworthy. Most important, if I had not been excused, I would have inflicted substantial punishments upon myself. If I had not been really sick but had still been perceiving myself as unable to meet my obligations, I would have believed my symptoms were an aspect of malingering or "all in my head." (It should be apparent that for a patient who went to the doctor with symptoms such as mine, the worst news that could be expected would be a diagnosis of severe and perhaps fatal 
malady. The next worst news, however, would be a diagnosis of no malady. The message "your health is excellent" is rarely a welcome response for the patient who feels incapacitated.)

The above case illustrates a process of blaming and excusing that is a regular part of medical practice. The key mechanism in this process is that the physician's failure to excuse results in blame or obligation for the patient. Sometimes, as in my case, the consequences of the physician's decision may not be "earth-shaking." Often, however, when physicians have to make decisions as to whether people will be viewed as disabled for long periods of time, or when financial remuneration depends on the physician's opinion as to the degree of disability, the decision whether to excuse may have a profound influence upon the patient and society. ${ }^{10}$ Considering the amount of wages, insurance payments, and other monetary awards it determines, the medical excuse-giving process influences the distribution of billions of dollars annually. 11

Some decisions to excuse the patient are easy to make. In the example given above in which there was a moderately severe biological illness associated with clear physical signs (fever) and definitive laboratory tests, the physician did not hesitate to excuse. Patients with mononucleosis and hepatitis are obviously disabled and need rest. Suppose, however, that after four weeks of bed rest my fever had gone down and my liver function tests had returned to normal but I still remained lethargic and still felt unable to work. At this point the physician's decision as to whether I should remain in bed and continue to be excused from obligations would have been much more difficult. Even if he gave me the benefit of the doubt and assumed that I was suffering from some of the residual effects of mononucleosis, he would have been concerned about whether the continuation of excuse-giving would be in the best interest of myself or my employers. If a longer period, say two months, had passed and I still complained of symptoms and claimed to be unable to return to work, the inclination of the physician to deny an excuse would have been much greater. He might have gently suggested that though I had been very sick it was time for me to resume my obligations, even if I found such action painful. He might have labeled my sedentary behavior a manifestation of some type of psychological illness. Such a tactic, as I will argue in a later section, would have provided me with a relatively fragile excuse, certainly not as powerful as an excuse of physical illness. Finally, he might have assumed I was malingering. It should be clear that anything less than a full excuse would have imposed aversive consequences upon me and would have complicated my relationship with my doctor.

10. See id. at 113. Theoretically, of course, physicians who evaluate patients in situations where compensation is at stake are only supposed to describe impairment to a judicial agency that is ultimately responsible for determining disability. In practice, the physicians' recommendations usually determine the final decision.

11. R. Berkhauser \& R. Haveman, Disability and Work: The Economics of American Public Policy 30, 37-38 (1982). 
In medical practice, the easy decisions, such as whether to excuse an acutely distressed patient, are less common than the difficult decisions that arise when distress is moderate and dysfunction is chronic. Often the degree of impairment the physician discovers does not explain the patient's substandard or deviant conduct. Yet, the patient may insist upon being excused and the physician may be under great pressure from the patient, his family, or his employers to provide an excuse. Dealing with this situation is one of the more ungratifying aspects of medical practice.

\section{IV}

\section{New Trends That Exacerbate the Doctor's Dilemma}

A number of social and scientific trends make physicians' decisions regarding excuse-giving even more difficult. Some trends direct physicians to hold their patients more responsible for ilness behavior; others direct them to hold them less responsible. The trend towards greater responsibility is in large part fueled by a new interest in promoting health and preventing disease by changing people's behavior. ${ }^{12}$ Traditionally, disease has been viewed as an affliction for which one is not responsible. ${ }^{13}$ This assumption is now being questioned. According to one leader in the field of public health, "the idea of a 'right' to health (guaranteed by government) should be replaced by the idea of an individual's moral obligation to preserve one's own health-a public duty if you will." 14 In the words of a Surgeon General's Report, "[p]ersonal lifestyles are responsible for a large share of unnecessary disease and disability in the United States."'15

Those looking at the question of health promotion and disease prevention note that the leading causes of death in the modern era are heart disease, cancer, stroke, accident, and suicide. ${ }^{16}$ These diseases are highly associated with willful activities such as smoking, alcohol and drug abuse, obesity, and lack of exercise. There seems little doubt that the people could live longer if they were able to change some behavior traditionally viewed as within the realm of choice and under control of the will. ${ }^{17}$

At the same time that physicians are being urged to hold patients to higher standards of responsibility, there are new discoveries in biomedical research that tend to make physicians more hesitant to ascribe responsibility for substandard or deviant behavior. The relevance of these new findings to the issue of responsibility is best understood by considering some problems in

12. Matarazzo, Behavorial Health and Behavorial Medicine: Frontiers for a New Health Psychology, 35 AM. Psycholocist, 807 (1980).

13. See generally L. King, Medical Thinking (1979).

14. J. Knowles, The Responsibility of the Individual, in Doing Better and Feeling Worse: Health IN THE UNITED STATES 57, 59 (1977).

15. Public Health Service, U.S. Dep't of Health, Educ., and Welfare, Healthy People: The Surgeon General's Report on Health Promotion and Disease Prevention 142 (1979).

16. See A. Antonovsky, Health, Stress and Coping 22 (1979).

17. See U.S. Dep't of Health and Human Services, Promoting Health-Preventing Disease: ObJeCtives fOR the NATION 61-62, 68-69, 79-80 (1980). 
defining the nature of the disease. In its simplest paradigm, disease can be said to be present when a biological deficit is demonstrable. ${ }^{18}$ There is not much problem in ascribing illness to a person with a broken leg or a high fever. Physicians and society in general have more difficulty in considering mental disorders as illnesses. Mental disorders are defined primarily on the basis of substandard or deviant conduct. ${ }^{19}$ Often no biological deficit can be demonstrated. Moreover, mental disorders are also so powerfully influenced by environmental factors that we think of them as being under control of the will. ${ }^{20}$ In dealing with these disorders physicians have been quite ambivalent. The mentally disordered are viewed as sick, but they are never treated with quite the same dignity as the physically ill. They are blamed and excused inconsistently.

The inconsistent response of physicians toward the mentally ill tends to diminish once it is possible to demonstrate some kind of biological variation that is associated with aberrant mental behavior. As evidence accumulates that major psychiatric disorders such as schizophrenia, mania, and depression are characterized by measurable biologic abnormalities, these disorders are increasingly legitimized as real diseases. ${ }^{21}$ New evidence has been recently discovered that even minor psychological deviations are likely to be associated with biological abnormalities. ${ }^{22}$ Scientists have always assumed that biological changes accompany changes in states of mind. However, the increasing demonstrability of the existence of these changes is new. New data that question the distinctions we commonly make between mind and brain also compound the problem of assessing the responsibility of either the physically or the mentally ill. ${ }^{23}$ At the same time that physicians are being urged to hold patients more accountable for their health, they are tempted to excuse a greater spectrum of behavior that is demonstrably linked to biological abnormality.

\section{Risk-Benefit Evaluations in the Medical Excusing Process}

While physicians obviously would benefit from having more precise guidelines for ascribing responsibility, research in this area or even efforts to conceptualize the problem are practically nonexistent. It is likely that many doctors do not even think about how they decide to grant or withhold excuses, but instead function intuitively or empirically. This section describes

18. See T. Szasz, The Mrth of Mental Illness $294-95$ (1961).

19. Adams \& Haber, The Classification of Abnormal Behavior in Comprenensive HandBook of Psychopathology 3 (H. Adams \& P. Sutker, eds. 1984).

20. Halleck, The Assessment of Responsibility in Criminal Law and Psychiatric Practice, in 1 LAw AND Mental Health: International Perspectives 193 (1984).

21. P. Wender \& D. Klein, Mind, Mood and Medicine: A Guide to the New Biopsychiatry 250-52 (1981).

22. See M. Reiser, Mind, Brain, Body 202-06 (1984).

23. These data are reviewed and summarized in F. Bloom, A. Lazerson \& L. Hofstadter, Brain, Mind, AND BeHavior 24 1-71 (1985). 
some of the conceptual issues involved in the medical process of ascribing responsibility. The material presented here is in large part a statement of what physicians could or should do and may not accurately describe what they actually do.

In deciding whether to excuse or to hold a patient responsible for a past or future act, the physician must evaluate the patient's past, present, or future capacities actually to perform that act. It is most difficult to decide if an excuse should be granted when the patient's physical incapacities are not severe enough to make it impossible for him to perform a particular act but are severe enough to make that act difficult for him. A patient who has a mild ankle sprain, for example, may be physically capable of performing as a postman, but performance is achieved only with considerable pain and with some risk to his future health. In most medical situations, impairments are partial and the physician's decision to excuse or not excuse cannot be made by simply determining the nature of the patient's incapacity. Instead, the physician must consider how that incapacity will influence a particular individual who exists in a particular environment. In effect, the physician must balance the potential benefits for the patient of performing or not performing a given act against the risk to the patient of performance or nonperformance. (Physicians may also consider the risks and benefits to society of performance of nonperformance, but these considerations will not be discussed here.)

In making risk-benefit evaluations, physicians can only speculate as to how the patient perceives either the pain or pleasure of various acts. The patient's view of risks and benefits may be quite different than that of his physician. Faced with this problem, the physician can make risk-benefit evaluations using either an objective or a subjective standard. The most tempting option is to adopt an objective standard and ask how a reasonable or rational person with the patient's disability might be expected to behave. Although this test has many precedents in law and is relatively uncomplicated, it is hardly practical in medicine. People have such different mental and physical capacities that it is extremely difficult to determine what is a rational or reasonable response to impairment. Two patients who have an identical injury are likely to feel quite different levels of pain. Even if reasonableness or rationality is viewed as the response of "most people" or "the average person," such a standard would still not deal efficiently with the actual needs of the patient.

It is ultimately more practical to evaluate the patient subjectively by estimating how the risk-benefit assessment of meeting obligations might appear to him. This task is exceptionally difficult. Patients probably do not perceive themselves as making risk-benefit assessments before deciding what they will do, and it is unlikely that any but a few patients would consider all risks and benefits. The physician is in the position of trying to decide what a particular patient would do if fully aware of all risks and benefits and capable of weighing them rationally. He must then consider granting an excuse when the subjective risks of a particular type of conduct appear to exceed the 
benefits. Such evaluations are most likely to be useful to the patient and society when they are based on accurate assessments of the patient's biological and psychological status.

\section{VI}

\section{Psychological Factors in the Medical Excusing Process}

The major problem of an individualized or subjective approach to assessment is determining how psychological factors such as cognitions or emotions influence the patient's perception of risks and benefits. A patient who experiences pain illustrates this relationship very well. We know that the amount of pain a patient experiences is partially determined by his view of his disability and his obligations. ${ }^{24} \mathrm{~A}$ patient who views his disability as incapacitating will experience more pain if he tries to work than a patient who does not. A patient who does not like his job will probably experience more pain if he returns to work than a patient who loves his job. The more intense experience of pain is not simply a matter of malingering. The pain is real and can be incapacitating. Similar considerations apply to the relationship of emotion to pain. Depression and pain are highly correlated; depressed patients are highly susceptible to the experience of pain. ${ }^{25}$

The psychological state of the patient must also be viewed in the systemsoriented context of the doctor-patient interaction. If the physician excuses the patient, he is perceived quite differently by the patient than if he does not. The patient's anticipation of the physician's response to his conduct may initially alert the patient's perception of the risks and benefits of that conduct. If the patient knows that the physician will disapprove of his not working, awareness of that attitude creates a new and formidable risk for him if he wishes to be excused from work.

Patients differ in their responses to the physician's stance on responsibility. Some patients who would not have met an obligation if the physician excused them are capable of meeting it without a great deal of discomfort if the physician withholds an excuse and encourages them to meet it. Other patients with identical physical capacities do not respond to the physician's directive. They may fail to meet obligations no matter how powerfully the physician urges them to do so. Do these differences in responsiveness mean that patients simply differ in the extent to which they are compliant or seek the physician's approval? Probably not. Other psychological differences must be present. One of the most important psychological variables is the manner in which people think about their own capacities for action.

24. Sternbach, The Psychologist's Role in the Diagnosis and Treatment of Pain in Patients, in Psychological Approaches to the Management of Pain 7 (J. Barger \& S. Adrian eds. 1982).

25. Von Knotting, The Experience of Pain in Depressed Patients, in 1 Neuropsychobiology 155 (1975). 
Social learning theorists have taught us that self-referent thoughts mediate the relationship between knowledge and action. ${ }^{26}$ The manner in which people view themselves, and particularly the manner in which they present messages to themselves that assess and evaluate the meaning events have for them, will have a significant impact on their behavior. In general, people are better able to maximize their performance when they are motivated to do so and view themselves as being capable of doing so. ${ }^{27}$ Cognitive processes that emphasize capability are especially important. High performing individuals tend to attribute causality for their behavior to internal rather than external control. ${ }^{28}$ They have a high sense of self-efficacy or a feeling of being in control of their destiny.

The views people hold and the messages they give themselves regarding their illnesses and their capacities to deal with them can be influenced by others. Patients can learn to feel more responsible for their performance by interventions, such as counseling, in which they are presented with different views of causality and self-determination. The physician's decision whether to excuse marks the initial step in the counseling process. It presents the patient with a message regarding self-efficacy that impinges upon the cognitive system he already has with regard to the issue of illness and disability. The nature of the physician's message will either strengthen or weaken feelings of self-efficacy. Physicians who wish to maximize the patient's performance will tend to withhold excuses. This withholding gives the patient the message that he can control his behavior. The physician's presentation of this message then increases the likelihood that the patient will improve performance.

Through all of this interaction the physician also must be constantly aware of the consequences of his actions. The danger of not excusing is that if the patient perceives himself as unable to perform his obligations, or as having to pay too high a price for performance, the physician's message may not have the desired effect. The patient advised to return to work may experience more pain than he finds tolerable. He may also feel unjustly blamed for having failed to meet past obligations. At this point he may become less trusting of his physician, less compliant, and more inclined to sabotage treatment. He may even escalate his symptomatology and develop new maladies to prove he is "really" sick. This complication is an extremely common problem in medical practice. ${ }^{29}$ The danger of excuse-giving is that it fails to take maximum advantage of the aspect of the patient's cognitive system that emphasizes his capacity to control his own conduct. It may confirm the patient's most negative views of the risks and benefits of

26. See Schunk \& Carbonari, Self-Efficacy Models, in Behavioral Health: A Handbook of Health Enhancement and Disease Prevention 230, 238 (V. Matarazzo, N. Miller, A. Herd, S. Weiss \& S. Weiss eds. 1984).

27. See Bandura, Self-Referent Thought: A Developmental Analysis of Self-Efficacy, in Social Cocnitive Development: Frontiers and Possible Futures 201 (J. Flavell \& L. Ross eds. 1981).

28. Bandura, Self-Efficacy: Toward a Unifying Theory of Behavioral Change, 1979 PsYCHOLOGICAL REV. 84, $191-215$.

29. Halleck, The Concept of Responsibility in Psychotherapy, 36 Aм. J. Psychotherapy 292 (1982). 
performances. As a result, the patient may not perform as well as he could have. He may respond to his poor performance with lowered self-esteem and increased guilt.

The physician has one other recourse in the excuse-giving process. He may conclude that some behavior is beyond the patient's capacities but that there is alternative behavior that is not. A patient who has recently sustained a back injury, who claims incapacity to return to his job as a manual laborer, and who takes to his bed may be physically incapable of meeting the obligations of his regular job. At the same time, he may not be so incapacitated that he cannot perform sit-down work. Here, the physician has the opportunity to grade the degree of the patient's responsibility. He might say, "You are excused from manual labor, but if there is less strenuous work available, you are obligated to do it." In making a recommendation for a lesser degree of responsibility, the physician will consider the same psychological process and risk-benefit evaluation involved in any assessment of responsibility.

Although the physician has many options in the process of excuse-giving, there is good reason for him to try to maximize responsibility whenever possible. Such a stance increases the likelihood that the patient's cognitive system will be reinforced or restructured in a manner that enhances performance. The resulting improvement fits in very well with the clinical experience of psychotherapists, or the common sense experience of parents trying to raise children. ${ }^{30}$ But there is much more involved here than the patient's or child's fear of punishment. Maximizing demands for responsibility creates a climate in which desirable change or growth is possible. Maximizing demands for responsibility gives people the message that they can control their behavior. When people believe that they are in control of their behavior and are choosing their actions, they not only function better, they feel better. ${ }^{31}$

The above analysis suggests that while the medical system excuses much more liberally than the legal system, both systems seek to maximize the responsibility of their clients. There is much more emphasis in the medical system, however, on maximizing responsibility for utilitarian purposes, particularly for the purpose of helping the patient.

\section{VII}

\section{Diseases of THE WiLl}

I have suggested earlier that physicians confront the most difficult problems of ascribing responsibility in dealing with mental disorders that are defined primarily on the basis of deviant behavior. ${ }^{32}$ Included in this group are disorders such as bulimia, obesity, anorexia nervosa, multiple personality

30. Mazer, The Therapeutic Function of the Belief in Will, 23 Psychiatry 45 (1960).

31. See generally J. Yalom, Existential Psychotherapy (1980).

32. See supra text accompanying notes 18-23. 
disorders, dissociative reactions, personality disorders, alcoholism, gambling, and sexual deviation. Although it has not been possible, thus far, to demonstrate a biological etiology for these conditions, patients who are given these diagnoses usually appear to be suffering. Their behavior does not ordinarily seem to be self-serving or adaptive. At the same time, however, the behaviors that define these disorders appear to be chosen or under control of the will.

Alcohol abuse is perhaps the most important disease of the will. Though alcoholics are often viewed as having a disease, the classical treatment of alcoholism requires an appeal to the will. ${ }^{33}$ Similar considerations apply to disorders such as gambling. ${ }^{34}$ Patients described as having multiple personalities sometimes have the capacity to bring on a new personality on demand and, under certain circumstances, appear able to restrain the appearance of a new personality. ${ }^{35}$ Patients with eating disorders seem to respond best to situations in which there are clear rewards and punishments. ${ }^{36}$ Relatively minor shifts in environmental contingencies may bring about major behavioral changes in these individuals, suggesting that their capacities to behave more adaptively have always been present. Similar considerations apply to personality disorders and sexual deviance. The behavior patterns are certainly difficult to modify over the long term. In the short run, however, people with personality disorders seem able to control histrionic or manipulative behavior and people with sexual disorders have the capacity to refrain from unacceptable sexual conduct most of the time. ${ }^{37}$

Physicians are ambivalent in dealing with patients who can be viewed as having diseases of the will. When physicians acknowledge the suffering of these individuals, they often treat them kindly and excuse many of their behaviors. At the same time, however, physicians never treat these patients quite as indulgently as other patients. There is a subtle quality of blaming involved in the approach to treatment and, indeed, treatment is often based on providing aversive consequences or punishment for the undesired behavior. Ambivalence about these disorders is sustained further by the physician's awareness that they often have serious and sometimes fatal physical consequences and by new knowledge that biological factors may, in part, cause them.

All of the considerations that apply to the process of excuse-giving with the physically ill are also relevant to the treatment of those with diseases of the will. The differences are in the complexity of the problem. In treating disorders that are partially under control of the will, physicians view the issue

33. Alcoholics Anonymous, Alcoholism Anonymous World Services (1955).

34. See Greenberg, Psychology of Gambling, in 3 Comprehensive Textbook of Psychiatry 327 (H. Kaplan, A. Freedman \& B. Sadock eds. 1980).

35. See Taylor \& Martin, Multiple Personality, 39 J. Abnormal Soc. Psychology 281 (1944).

36. Miller, Eating Disorders, in Compenensive Handbook of Psychopathology 675, 676 (H. Adams \& P. Sutker eds. 1984).

37. See Adams \& Chiodo, Sexual Deviations, in Comprehensive Handbook of Psychopathology 777 (H. Adams \& P. Sutker eds. 1984). 
of responsibility as paramount, and excuse-giving must be considered on a day-to-day or almost hour-to-hour basis. The emphasis on maximizing personal responsibility may also be somewhat greater. ${ }^{38}$

When we begin to view people who gamble, have deviant sexual tendencies, or have personality disorders as individuals who may be sick and should not always be adjudged fully responsible for their actions, it is not a very large step to apply similar considerations to chronic criminal offenders. Criminals as a group do not have as many capacities or opportunities as noncriminals. ${ }^{39}$ Their assessments of the risks and benefits of criminal action often favor antisocial conduct and they usually find the choice to behave in a conforming way to be a difficult one. Some of the difficulty may be related to social disadvantage and lack of socially acceptable alternatives. Often, however, biological and psychological incapacities make their choices more difficult. Many criminals have a defective intellect, learning disorders, or other minor biological variations that may impair their capacity to develop constructive alternatives to crime. A variety of genetic or acquired biological variations or aberrent learning experiences may also impair the capacity of criminals to assess the risks and benefits of law-abiding versus criminal conduct in various situations. ${ }^{40}$ Because there is ample evidence that the majority of crimes that result in arrest are committed by people who are intoxicated, it can be asserted that most offenders have, at least, some mental incapacity at the time of the crime. ${ }^{41}$

There may be other reasons for viewing crime as illness. Granting that a great deal of criminal activity is rational and self-serving, it must also be acknowledged that much of it is not. Often the criminal takes enormous risks for negligible benefits and suffers greatly when he is unsuccessful. Crime is also difficult to distinguish from illness on the basis of the harm it causes others. The social harm created by some diseases of the will such as alcoholism or gambling may be no less than those created by many crimes. Sometimes the same socially harmful behavior is defined as both a mental disorder and a crime. Exhibitionism, voyeurism, and sexual sadism are defined as mental disorders in official psychiatric nomenclature. ${ }^{42}$ When individuals are apprehended for engaging in such activities, they are also viewed as criminals.

The tendency to view crime as illness has a long and controversial history in modern society. While this view has certainly had its advocates, it has had a limited impact upon the criminal justice system. In most societies a medical approach to crime has been rejected because it is believed to foster a model of

38. See Halleck, The Concept of Responsibility in Psychology, 36 AM. J. Psychotherapy 292, 296-97 (1982).

39. See Glaser, A Review of Crime-Causation Theory and Its Application, in 1 Crime AND JUSTICE 103 (N. Morris \& M. Tonry eds. 1979).

40. See Mednick \& Volavka, Biology and Crime, in 2 Crime and Justice 116, 116-17 (N. Morris \& M. Tonry eds. 1980).

41. See generally Y. Rennie, The Search for Criminal Man (1978).

42. Diagnostic and Statistical Manual of Mental Disorders 271-73 (3d ed. 1980). 
responsibility that is incompatible with societal needs for law and order. It is also regularly dismissed as an impractical way of dealing with the criminal. ${ }^{43}$ Yet, the conceptual framework for viewing criminals as patients exists, and no scientific premises would be violated if this framework were adopted. The decision of our society to hold criminal conduct to different standards of responsibility than behavior during illness is based on perceived societal needs, not on scientific assessment of the capacities of criminals or patients. In the next section, the possible advantages of a medical model of excusegiving in the criminal justice system will be considered.

\section{VIII}

\section{Responsibility in the Criminal Justice System}

One of the major differences between excuse-giving in medicine and in the criminal justice system is the degree of attention given to individual capacities. Medicine excuses deviant conduct based on assessments of the patient's capacities. The criminal justice system pays almost no attention to differences in capacities among offenders. The mentally defective person and the genius are equally liable if they forge a check. As noted previously, psychological, biological, or sociological differences provide an excuse only in rare instances. The insanity defense is rigidly defined so that the offender is only excused if he exceeds a threshold of extremely severe impairment. ${ }^{44}$ This means that many who are gravely incapacitated are held to the same standard of blameworthiness as those who are perfectly normal. Consideration of individual differences sometimes plays a role in sentencing, but this individualization happens only after blameworthiness has been determined. Even then, differences in capacities may be ignored in determining the degree of punishment imposed. ${ }^{45}$

By assessing punishment in a fixed manner, the criminal justice system also differs from most other systems that impose blame and punishment. In the medical system a person who is not excused for being sick faces a variety of internal and external aversive consequences whose intensity may be modified by the physician. The physician can modify these consequences by changing the demands put on patients. Patients can also be partially or fully excused, that is, held responsible for performing some, but not necessarily all, aspects of a task. The decision to excuse or not excuse can also be rescinded at any time the patient's capacities change. All such flexibility is lacking in the criminal justice system where the emphasis is upon the infliction of a specific degree of pain, usually created by depriving the offender of liberty and forcing him to live under hard conditions for a relatively precise period of time.

43. MacNamara, The Medical Model in Corrections, Requiescat in Pace, 14 Criminology 439 (1977).

44. See S. Halleck, The Mentally Disabled Offender (Forthcoming NiMH Monograph).

45. See L. Forer, Criminals and Victims 153 (1980). 
Although the retributive needs of society and victims of crime may be served by fixed sentencing, this practice leaves little room for dealing with differences in capacities among offenders. Imposing equal or similar prison sentences upon offenders who have committed the same crime, but who have different capacities to have chosen otherwise, violates a fundamental sense of fairness. Furthermore, because offenders are psychologically, sociologically, and biologically different, imprisonment, the standard form of punishment, hardly affects all offenders in the same way. The amount of pain inflicted upon offenders given equal sentences for the same crime can never be experienced by them as an equal punishment. ${ }^{46}$ Three days in prison for one individual may be as painful as three years for another individual. If they are both sentenced to three years of imprisonment, the former may suffer more than a thousandfold the punishment of the latter.

The failure of the Anglo-American criminal justice system to consider differences in individual capacities in determining blame and punishment can be viewed as a conceptual and structural flaw, which renders it fundamentally unjust and inefficient. The current emphasis on retribution and desert complicates efforts to meet the utilitarian purposes of deterring crime, protecting society, and rehabilitating offenders. There is little reason to believe that a system of fixed sentencing efficiently serves the purposes of deterrence.

Holding those who are gravely impaired to the same standard of accountability as those who are more generously endowed might, in theory, discourage all potential offenders. It should, at least, discourage those who might commit crimes hoping that their impairments would generate leniency. Research on the deterrent effect of punishment, however, suggests that these speculations may be irrelevant. ${ }^{47}$ It appears that criminals do not dwell on their own capacities or what will happen to them in the sentencing process when they commit a crime. Severity of punishment and deterrence do not appear to be directly correlative. It is probable that offenders are more significantly influenced by the certainty and swiftness of punishment. ${ }^{48}$ In a democratic society, fixed and severe sentencing initiates complex and lengthy legal battles that may actually diminish the certainty or celerity of punishment, eventually diluting the powers of punishment.

Fixed sentencing based on the principle of "just desert" also fails to insure the restraint of offenders who are at high risk of committing another crime. Unless sentences are extremely long, many offenders who have served their sentences will return to the streets with the same impairments that made them likely candidates for criminal behavior in the first place. Fixed sentencing leaves no option for dealing with the offender whose capacities change while in prison so that his risk to society changes.

46. S. HaLleck, supra note 44.

47. See Grasmick \& Bryjak, The Deterrent Effect of Perceived Severity of Punishment, 59 Soc. Forces 471 (1980).

48. See Pestello, Deterrence: A Reconceptualization, 30 Crime \& DelinQ. 593 (1984). 
The current system of criminal justice fails profoundly in the area of rehabilitation. Rehabilitation is given little credence as as goal of criminal justice.49 A number of studies have suggested that offenders cannot be rehabilitated (at least under current conditions), and civil libertarians have argued that the measures taken to rehabilitate offenders, including indeterminate sentencing, may ultimately be more harmful to them than being left alone for a fixed period of imprisonment. ${ }^{50}$ In spite of these critiques, there is good reason to take the goal of rehabilitation seriously. Recent data from a variety of sociological and biological disciplines indicate that a relatively small number of offenders commit a large number of serious crimes. $^{51}$ One response to such data is, of course, to try to identify these people and monitor them for long periods of time. If such an approach is not possible, however (and it rarely is), rehabilitation of these offenders emerges as having a powerful utilitarian value for society. It is likely to be cost efficient as well as humane. ${ }^{52}$

In considering rehabilitation, it is useful to ponder why treatment works so well in the medical setting but so poorly in the correctional setting. There are many reasons for this difference, including perhaps some basic differences between antisocial behavior and other forms of aberrant behavior that are defined as illnesses, but at least one reason must relate to the emphasis the criminal justice system puts on retribution. Under a retributive approach which emphasizes fixed prison terms, the offender has little incentive to change. If he knows that he faces years of punishment irrespective of possible behavioral improvement, he can hardly become enthusiastic about rehabilitation. In addition to feeling resentful for what he usually perceives as excessive and undeserved punishment, he will feel little sense of responsibility for shaping his own destiny. This disincentive to change contrasts with the situation of the patient in medical practice who can modify the excuse-giving or excuse-withholding response of the physician by exhibiting changed behavior. Efforts to invoke responsibility based on concepts of retribution lack the flexibility of similar efforts based on principles of utility. This lack of flexibility may be a fatal handicap to the goal of rehabilitation in modern correctional justice.

\section{IX}

\section{Implications of THE Medical Model of Excuse-Giving for Criminal Justice}

The conceptual framework of medical excuse-giving described in the first part of this article ${ }^{53}$ might influence the criminal justice system in various ways. One might argue that fundamental fairness requires that responsibility

49. See generally F. Cullen \& K. Gilbert, Reaffirming Rehabilitation (1982).

50. M. Schwartz, T. Clear \& L. Travis, Corrections and Issues Approach 194-205 (1980).

51. Wolfgang, Crime in a Birth Cohort, 107 Proc. Am. Phil. Soc'y 404 (1973).

52. S. Halleck, The Mentally Disordered Offender (Forthcoming NIMH Monograph).

53. See supra sections II-VI. 
be ascribed on the basis of an individual's capacities at the time of the crime. It can be logically argued that if two individuals do not have the same capacities to refrain from committing a criminal act, they are not equally responsible for the same act and should receive different degrees of punishment. While such an approach would be consistent with scientific principles, it is probably impractical. It would require the consideration of complex biological, psychological, and sociological factors in every determination of criminal liability. Excuse-giving would be enormously expanded but the process would be much more cumbersome than it is in medicine, since each excuse would have to be litigated under some legal theory or doctrine. The ordinary trial might become as complicated as a contested insanity defense trial. Our courts could not tolerate such a burden.

A second approach might be to leave the assessment of capacities to the judge or jury at the sentencing phase of the trial. To a certain extent such a system of imposing sentences is in operation now. In the current system, however, judges or juries rarely take a careful look at the biological, psychological or social capacities of the individual offender. Nor do they have a great deal of flexibility in imposing sentences. There is, however, a practical problem with expanding consideration of individual variations in the sentencing phase of the trial. To the extent this approach is maximized, the burdens on the courts would be overwhelming, just as it would be if these considerations were taken into account at the trial stage. A sentencing hearing which deals with biological, social, and psychological incapacity could become as complicated as a trial in which the same factors are considered for the purpose of determining guilt. ${ }^{54}$

There is still one other approach to the management of offenders that deals with individual differences and also incorporates some aspects of the medical approach to responsibility. This solution calls for a system of indeterminate sentencing that allows for confinement and treatment of offenders, not for a fixed period of time, but rather for as long as they continue to need treatment and represent a threat to public safety. Indeterminate sentencing draws heavily on medical principles insofar as it views criminality as a condition that can be treated. It is also concerned with societal needs and provides for indefinite restraint of those who appear to be dangerous. In these respects, it is most similar to the medical model used in treating the severely mentally ill. This model is somewhat different from that which has already been described as characterizing other aspects of medical practice. The emphasis on restraint of those considered dangerous, in either a system of indeterminate sentencing of criminals or involuntary confinement of the mentally ill, requires some reconceptualization of the process of excuse-giving.

It can be argued that the patient who is involuntarily hospitalized for treatment of mental illness is simply excused from all obligations to function

54. See generally Task Force on the Role of Psychiatry in the Sentencing Process, Am. Psychiatric Ass'n, Psychiatry in the Sentencing Process (1984). 
in society and that, as he gets better, he is held more responsible for his conduct. Such a view ignores the possibility that the patient will view his confinement as punitive, as an aversive consequence deliberately imposed upon him because of substandard or deviant conduct. The patient may, in effect, view hospitalization as the result of a failure to be excused. Physicians try to ignore this view because they have no punitive intentions. Indeterminate sentencing of offenders, however (which bears many resemblances to involuntary commitment of mental patients), is not based entirely on utilitarian principles. When offenders are sentenced to indeterminate programs, some punishment is intended and past criminal conduct is not excused. Nor is it likely that the offender will view deprivations of his liberty as an excuse from meeting current societal obligations. Furthermore, the severity of the punishment is not tempered by considering the offender's deficiencies of capacity. Rather, punishment is terminated when capacities improve and when the offender is judged less dangerous. Excuses from aversive consequences in an indeterminate sentencing program begin to exert influence as the offender gets better, not "worse."

Bearing in mind the differences that consideration of the concept of dangerousness creates in the excuse-giving process, there are still formidable advantages to the indeterminate model of sentencing in criminology. In such systems the degree of punishment is based less on desert and proportionality than on consideration of individual differences. In contrast to a system of fixed sentencing, offenders know that punishment will be terminated if they "get better." They can then be held responsible for using all of their capacities and efforts to change their deviant conduct. Once confined, they can be held to a much higher standard of responsibility than they would experience in a model of fixed sentencing. Treatment processes can proceed as they do in medical practice and the utilitarian model of medical excusegiving can be fully utilized.

Indeterminate sentencing, like the medical model that spawned it, has had only transient periods of popularity in criminal justice. Currently, there are few indeterminate programs operating in the United States, and the dominant sentencing philosophy favors fixed and rigid terms of punishment. ${ }^{55}$ There seems to be general agreement that indeterminate programs don't "work." Whatever the term "work" might mean in this context, there is no evidence that indeterminate sentencing is any more or less conducive to public safety than fixed sentencing. Data as to the impact of alternative modes of sentencing on subsequent crime rates are simply not available. ${ }^{56}$

Perhaps the strongest criticism of indeterminate sentencing has focused upon the needs of the individual offender. Indeterminate sentencing creates inequities and can compromise the rights of the offender. An individual who

55. Dix, Special Dispositional Alternatives for Abnormal Offenders: Developments in the Law in MENTALLY Disordered Offenders 133, 133-36 (J. Monahan \& H. Steadman eds. 1983).

56. Monahan \& Davis, Mentally Disordered Sex Offenders, in Mentally Disordered Offenders 200 (J. Monahan \& H. Steadman eds. 1983). 
spends more time in prison than another who committed the same crime will perceive himself as being treated unfairly, even if his incarceration is serving a societal goal of restraint or rehabilitation. This type of inequity is unavoidable. Whether it is more unjust than the inequities created by fixed and identical sentencing of individuals with markedly different capacities, however, is arguable.

The greatest threat of indeterminate sentencing to the civil rights of offenders is that it puts them at risk of being punished for longer periods of time than they deserve (under a desert theory) in order to serve societal needs of restraint or rehabilitation. This risk is similar to the risk of harm imposed upon the mentally ill who are involuntarily restrained even when they are undeserving of punishment. ${ }^{57}$ These risks can be substantially reduced in either the criminal justice or mental health system by establishing careful procedures for judicial monitoring of any period of prolonged restraint. In the criminal justice system such monitoring is especially important when incarceration is extended beyond the time the individual would have been sentenced to serve under a desert model. Harm to offenders could be minimized if continued restraint were imposed only when convincing proof of dangerousness was available and when there was strong evidence that the offender was making progress towards rehabilitation. Another means of reducing the risk of harm in the criminal justice system is to set maximum sentences. Under maximum sentences, indeterminancy could be maintained as a principle that would allow for early release but would not permit punishment beyond that which is deserved.

Indeterminate sentencing is also criticized for imposing an uncertainty upon offenders that is overly stressful, and for encouraging them to manipulate the system by constantly seeking to prove they are not dangerous and have been rehabilitated. ${ }^{58}$ The first of these assertions is simply a speculation unsupported by data. Perhaps the possibility of early release would create a kind of hopefulness that would compensate for uncertainties regarding the exact time of release. The second assertion may be true but it is hardly a problem. Incarcerated individuals will regularly use a variety of manipulative methods to gain release. Skilled correctional personnel should not be deceived by these maneuvers. Furthermore, the efforts of offenders to portray themselves as "healthy" are not necessarily detrimental to the process of rehabilitation. Experimenting with a "healthy" role may be a first step towards desirable behavioral change. ${ }^{59}$

57. N. Kittrie, The Right to Be Different 35-36 (1971).

58. See generally N. MORRIS, THe FUtURe OF IMPRISONMENT (1974).

59. See generally S. Halleck, Psychiatry and the Dilemmas of Crime (1967). 


\section{$\mathrm{X}$}

\section{CONCLUSION}

I have presented a series of arguments for moving towards a medical model of criminal justice based on placing greater emphasis on utilitarian principles. Implementation of such a model would necessitate increased reliance on indeterminate rather than fixed sentencing. Although the social and moral climate of our times opposes such change, I believe that scientific progress will make it inevitable.

Biomedical research is progressing to a stage where distinctions between concepts such as mind, brain, or body are no longer as rigid or as certain as we once thought they were. Persons and minds are changed by altering the brain. Whether we wish to define that aspect of a person's behavior that is changed by altering the brain as a disease or as a tendency towards criminal behavior, the process of change is the same. It is only a matter of time before new biological methods of treating crime by altering brain chemistry are available. ${ }^{60}$ Some technologies such as anti-androgen treatment of sexual deviation are already in widespread use. ${ }^{61}$ As newer, more efficient, and safer technologies develop, pressures for their use in some type of medical treatment approach will be irresistible.

Those who fear that movement towards a medical model of criminal justice will minimize our society's commitment to the doctrine of individual responsibility may be reassured by considering the manner in which physicians deal with the concept of responsibility. I have argued that in treating most forms of disease physicians should and, in actuality, probably do try to maximize responsibility. They do not do this simply because they are wedded to any philosophical position regarding "just deserts," or the existence of free will. Rather, they have come to appreciate that whether the idea of a will is reality or metaphor, appeals to the will have a powerful influence on behavior. Behavior defined as either "sick" or "bad" is most likely to change in a socially desirable manner when its perpetrator is held fully responsible for using all of his capacities to control it. This simple truth provides a link between science and morality which might foster the development of new approaches to criminology.

60. Moyer, What is the Potential for Biological Violence Control?, in Biology ANd Crime 18 (C. Jeffrey ed. 1979).

61. Walker \& Meyer, Medroxyprogesterone Acetate Treatment for Paraphilial Sex Offenders, in VIOLENCE ANd The Violent Individual 353 (J. Hans, T. Roberts \& K. Solway eds. 1981). 